\title{
FOREWORD
}

\section{Quantitative economic analysis in European fisheries: models of fleet behaviour and catchability}

\author{
Sean Pascoe ${ }^{1, a}$, Ragnar Arnason ${ }^{2}$ and Erik Lindebo ${ }^{3}$ \\ ${ }^{1}$ CSIRO Marine and Atmospheric Research, 233 Middle Street, Cleveland, Queensland, Australia \\ 2 Department of Economics, University of Iceland, 101 Reykjavik, Iceland \\ 3 European Commission, DG Maritime Affairs and Fisheries - Structural Policy and Economic Analysis, Rue Joseph II 99, \\ 1049 Brussels, Belgium
}

$\mathrm{M}$ ost modern fishing nations recognise the need to go beyond purely biological considerations when managing fisheries. This recognition generates a demand for models that combine both the biological and economic facets of the fishery, namely bioeconomic models. In order to use bioeconomic models for fisheries management purposes, the models need to include behavioural assumptions - either explicitly as endogenous sub-models or implicitly as imposed behaviour - which simulate how management actions affect fishers' behaviour and, subsequently, the state of the fish stocks. Causal relationships in bioeconomic models are generally complicated. Management affects the economic performance of the fleet and, thus, creates incentives for fishers to alter their behaviour. This altered fishing behaviour affects the fish stocks, which in turn feed back to further change the incentives faced by fishers. This further influences their behaviour and the biological, ecological, and economic outcomes of the fishery. This web of actions and reactions may lead to very complicated dynamics in the fishery over time.

In some countries, such as Australia, bioeconomic models are being used directly in setting catch and effort targets for some fisheries, while economic assessments form part of the annual fisheries status assessments. Similar use of bioeconomic models takes place in other advanced fishing nations such as Iceland, New Zealand and Canada. In the European Union, considerable interest is developing in the potential use of bioeconomic models for management advice ${ }^{1}$

\footnotetext{
a Corresponding author: sean. pascoe@csiro.au

1 A recent tender from the European Commission called for a study of the potential usefulness of existing bioeconomic models and available economic data for the provision of management advice, and how future models may need to be developed to meet the needs of the Commission (European Commission Call for Tenders FISH/2007/07).
}

and considerable attention is being paid to the collection of appropriate economic information.

The construction of bioeconomic models for management advice requires more than just adding prices and costs to biological models. It generally requires a major empirical measurement and modelling effort. In addition to the biological part, it requires development of models of fisher behaviour, for example, to determine how effort levels may change in response to the incentives created by management. These include models of entry and exit, models of generation of fishing effort and how it is allocated over time, fisheries and fishing grounds, and the implication of these responses for overall fleet performance. Similarly, models of price formation are required, and an understanding of how costs change under different management systems. In most cases, these models can provide valuable information for fisheries management even without integration into a full bioeconomic framework.

In July 2007, a session at the biennial conference of the European Association of Fisheries Economists (EAFE), organised by the Institute of Economic Studies (IoES) University of Iceland, focused on the development of quantitative economic models for management advice in a session entitled "Advances in fisheries analysis and modelling". The session attracted 12 papers, five of which are presented in this issue of Aquatic Living Resources. These selected papers focus on fleet dynamics and behaviour, as well as productivity related aspects of fisheries production. A brief outline of each of these selected papers is presented below, following a brief description of the EAFE itself.

\section{European Association of Fisheries Economists (EAFE)}

Founded in 1989, EAFE is an independent association of economists working in fisheries and related industries in the 
member states of the European Economic Area (EEA). The objectives of EAFE include promoting cooperation in research in fisheries and aquaculture, assisting the dissemination of information about fisheries economics among members, and furthering understanding of the economics of fisheries and aquaculture. This is largely realised through the biennial conferences, which provide an opportunity for researchers to share ideas, network and develop new research collaborations.

EAFE currently has around 100 individual members that undertake economic research and analysis of the catching, aquaculture and on-shore sectors. EAFE also has seven corporate members representing key institutions within the EEA with an interest in fisheries economics research. For further information about EAFE and its activities, please visit www.eafe-fish.eu.

\section{Overview of the selected papers}

The five selected papers are largely concerned with modelling changes in effort levels in response to management changes. These include two different approaches to modelling entry and exit, or investment and disinvestment, behaviour; two models of fleet dynamics incorporating entry/exit behaviour; and an analysis of the implications of various assumptions about catchability in bioeconomic models.

\subsection{Entry and exit behaviour}

Many, perhaps most, ocean fisheries exhibit a greatly excessive number of fishing vessels. Obviously, therefore, it is potentially very useful for fisheries managers striving to reduce fishing fleets to be enlightened about the factors that are most important in the exit decision. The paper by del Valle et al. describes a logit model of the stay/exit decisions by owners of fishing vessels. In the paper, del Valle and her co-authors label this class of decisions "long term behaviour" on the assumption that once a vessel has exited the fishery, re-entry is difficult if not impossible. This assumption may not be valid for all fisheries, as there are many empirical cases of temporary exits of vessels and even firms from fisheries. However, the paper makes a real contribution in that it provides an explanation of fishers' stay/exit decisions irrespective of whether they are for the long or short term. While their information relates to a particular empirical case, namely the Basque inshore fishery, the result may, with the usual qualifications, be generalized to fishers in general.

Basing their inferences on cross-section data from 2003 and 2004 and state-of-the-art econometric techniques, del Valle and her co-authors find that socio-economic factors such as the vessel owner's age, his skill and experience and the existence of an heir (son) to continue the business seem to have a large impact on the decision to exit. Economic factors such as outstanding loans and decommissioning grants were also found to play a significant role with both increasing the likelihood of exiting. This is as expected by economic reasoning. By contrast, profitability, while having the correct sign, was not found to significantly affect the exit decision.
In the paper by Haraldsson, a Cox proportional hazard model is developed to examine exit behaviour. The main difference between hazard regression models and discrete outcome models (such a the logit model used by del Valle et al.) is that the former takes into account the timing of alternative outcomes explicitly, making it possible to separate the timing aspect of the decision to exit or entry from the effect of other firm- or industry specific factors. In this case, the effects of different effort restriction systems on Icelandic vessels not participating in the individual transferable quota system were examined. These restrictions were applied to mostly small vessels, and included limits on the number of days that could be fished.

The results of Haraldsson's analysis suggest that small vessels not subject to quota have benefited from the existence of the ITQ scheme. This positive externality arises as a result of autonomous adjustment and subsequent capacity reductions in the fleet of larger vessels. As a result, ITQs in the larger vessels may have encouraged the entry and reduced the rate of exit of the smaller vessels. In contrast, reducing the allowable days at sea did not seem to increase the likelihood that small vessels would exit, suggesting that in this particular case effort controls were relatively ineffective as a capacity management measure for the fleet.

\subsection{Fleet dynamics models}

The paper by Stouten et al developed and applied a system dynamics model incorporating models of entry and exit and effort allocation to determine how different management approaches affect fleet performance. The model was developed for the Belgian fleet, and included four fleet segments: shrimp trawlers, eurocutters, large beam trawlers and netters. In the model, vessels enter, exit or stay in the fishery depending on a set of criteria being achieved (related to accumulated savings over time and earnings - both of which may be negative depending on the conditions in the fishery). The simulation model was used to compare the outcomes under three different management strategies - days at sea restrictions, aggregate quota and removal of vessel licences. The simulations were run stochastically.

Although similar to the Haraldsson paper in intent, the outcomes of the analysis were substantially different. Changing days at sea and aggregate quota levels was found to result in substantial fluctuations in economic performance compared to reducing the number of licences. This result is not surprising, as it is well recognised that a smaller fleet is more resilient to shocks than a larger fleet managed through sub-optimal controls. Where the main contribution of the paper lies is in its demonstration that highly non-linear and complex systems can result in unexpected behaviour. In numerous simulations counterintuitive behaviour of fleet performance and dynamics due to certain policy changes was observed. Termed "misperception of feedback" by authors, and similar in concept to chaos theory, Stouten et al. demonstrate that fisheries management plans do not always work the way they are expected to, and that models such as this can provide managers with a likely range of outcomes that take into account the complexity and feedback within the system. 
Hoff and Frost also developed a simulation model to examine management changes (again quota and effort regulations) taking into account fleet dynamics and investment behaviour. The model is applied to the Danish seiners catching cod in the North Sea. Investment is modelled as a function of discounted expected future profits, with expectations based on the most recent estimates of profit.

An interesting feature of the model is that management regulations (principally quota levels and maximum days at sea) are determined endogenously based on a harvest control rule. The harvest control rule determines the total allowable catch for a given time period based on the estimated spawning stock at the end of the previous time period. The model may then be used to evaluate the management strategy as a whole, not just the instruments used as in the Stouten et al. model.

\subsection{Catchability}

The paper by van Oostenbrugge et all examines the concept of catchability in fisheries bioeconomic models. Any bioeconomic model includes some form of a harvesting function. One component of this harvesting function is catchability which helps to translate fishing effort and stocks into harvests. As a general rule, the higher the catchability, the less fishing effort is needed to generate a given level of harvest. Thus, catchability is one of the main determinants of the economics of fishing. The paper points out that in many bio-economic simulation models catchability is assumed to be constant, i.e. independent of the level of fishing effort and, presumably, fish stocks. This assumption, according to van Oostenbrugge et al. is not empirically tenable. In their paper, they provide empirical evidence from the Dutch beam trawl fishery that the catchability, far from being a constant, is actually a declining function of fishing effort.

Obviously, catchability declining in fishing effort has far-reaching implications for fisheries policies. From a purely technical perspective, it suggests that harvest functions are not linear but concave in fishing effort. One practical implication of this, as van Oostenbrugge et al. point out, is that limitations on aggregate fishing effort will lead to increases in average catchability and, therefore, less than proportionate reduction in harvests. If that is the case, and fisheries management relies to a certain extent on effort limitations, it becomes very important to measure the curvature of the catchability function. Otherwise, the harvest reductions resulting from effort limitations will not be predictable.

\section{Significance}

The economic modelling papers presented in this issue of Aquatic Living Resources represent just a fraction of the fisheries economics research activity currently being carried out in Europe. Although the focus of these studies has been on European fisheries, the modelling techniques, and in some cases the results, are applicable to a wide range of fisheries internationally.

The development of such models provides valuable tools to managers. Adoption of such tools by managers is the next step if fisheries are to be managed effectively to ensure favourable future economic as well as biological outcomes.

\author{
Sean Pascoe \\ CSIRO Marine and Atmospheric Research, 233 Middle \\ Street, Cleveland, Queensland, Australia \\ Ragnar Arnason \\ Department of Economics, University of Iceland
}

Erik Lindebo

European Commission, DG Maritime Affairs and Fisheries Structural Policy and Economic Analysis, Rue Joseph II 99, 1049 Brussels, Belgium 